\title{
REVIEW
}

\section{Magnesium in stroke treatment}

\section{K W Muir}

Postgrad Med J 2002;78:641-645

Magnesium is involved in multiple physiological processes that may be relevant to cerebral ischaemia, including antagonism of glutamate release, NMDA receptor blockade, calcium channel antagonism, and maintenance of cerebral blood flow. Systemically administered magnesium at doses that double physiological serum concentration significantly reduces infarct volume in animal models of stroke, with a window of up to six hours after onset and favourable dose-response characteristics when compared with previously tested neuroprotective agents. Small clinical trials have reported benefit, but results are not statistically significant in systematic review. A large ongoing trial (IMAGES) will report in 2003-4 and further trials are planned.
Correspondence to: Dr Keith W Muir, University Department of Neurology, Institute of Neurological Sciences, Southern General Hospital, Glasgow G5 1 4TF, UK:

k.muir@clinmed.gla.ac.uk

Submitted 28 May 2002 Accepted 12 July 2002
$\mathrm{F}$ or 15 years, neuroprotective agents have promised to add to the limited therapeutic armamentarium for acute ischaemic stroke, but have as yet delivered nothing. Despite major reductions in infarct volume in animal models of focal cerebral ischaemia by drugs that embrace a multitude of mechanisms of action, a succession of clinical trials in acute stroke have failed to translate histological animal effects into clinical improvement. ${ }^{1}$ The bones of abandoned drug development programmes have been thoroughly picked over in a bid to find reasons for these failures, and a mixture of inadequate animal data, poorly established pharmacokinetics, dose limiting tolerability problems, and overoptimistic trial design have variously been proposed as culpable. $^{2-4}$ Magnesium sulphate is currently undergoing clinical trials in acute stroke: will this be the compound to break the mould and finally confirm the neuroprotection hypothesis?

\section{GENERAL PROPERTIES OF MAGNESIUM}

Magnesium ions have a physiological role in multiple processes pertinent to ischaemia. In the brain, magnesium is predominantly complexed with adenosine triphosphate (ATP), and is an important cofactor in cellular energy metabolism and protein synthesis. ${ }^{5}$ Brain magnesium concentrations are regulated by active blood-brain barrier transport that maintains cerebrospinal fluid concentrations higher than those in serum (typically $1.1 \mathrm{mmol} / \mathrm{l}$ compared to $0.8 \mathrm{mmol} / \mathrm{l}$ ). ${ }^{6}$ Cerebrospinal fluid magnesium concentration increases by $20 \%-25 \%$ after typical intravenous or intramuscular treatment regimens both in animals and in humans, and peaks around four hours after parenteral administration. ${ }^{78}$ Magnesium concentration is selectively increased in regions of pathology in animals, including focal ischaemia9 and seizures. ${ }^{7}$ Intracellular free magnesium concentrations increase in ischaemic stroke, presumably largely through dissociation from ATP. ${ }^{10}$

Magnesium generally antagonises calcium in biological systems, ${ }^{11}$ for example relaxing vascular smooth muscle and inhibiting calcium mediated activation of intracellular enzymes. Therapeutic uses of magnesium principally include obstetric use to prevent seizures in preeclampsia/eclampsia, ${ }^{12}{ }^{13}$ and use in cardiology to prevent dysrhythmias. Wider cardiological application as a possible cytoprotective agent in acute myocardial infarction was suggested by metaanalysis $^{14}$ and a moderate sized trial, ${ }^{15}$ but seemingly refuted in a very large open study, the fourth international study of infarct survival (ISIS-4). ${ }^{16}$ The possible failure of ISIS-4 to test magnesium in a biologically relevant manner has led to continued debate and further trials in myocardial infarction. ${ }^{17} 18$

Magnesium is an attractive therapeutic agent: it is inexpensive, widely available, and intravenous or intramuscular administration yields predictable serum concentrations. Therapeutic effects are observed in pre-eclampsia at serum concentrations 2-3 times physiological (1.6-2.4 $\mathrm{mmol} / \mathrm{l}){ }^{19}$ Magnesium is normally excreted by the kidneys with a half life of four hours or less, and adverse effects generally arise only in patients with significant renal impairment or in situations of iatrogenic overdose. Overdose can be detected clinically by loss of deep tendon reflexes (occurring at concentrations of $3.5 \mathrm{mmol} / \mathrm{l}$ and greater), and administration of calcium gluconate generally avoids significant problems. In rare cases, where serum concentrations are $5 \mathrm{mmol} / \mathrm{l}$ or greater, more profound neuromuscular block may necessitate temporary ventilatory support. ${ }^{20}$ Since conduction is slowed throughout the heart, symptomatic bradyarrhythmias may arise in individuals with heart block, but if used correctly, the risk of this even in patients with acute myocardial infarction in ISIS-4 was only $0.3 \%$. The reasonably wide therapeutic index for magnesium contrasts with many synthetic neuroprotective agents which have been associated with

Abbreviations: ATP, adenosine triphosphate; FAST-MAG, Field Administration of Stroke Treatment-Magnesium (trial); IMAGES, Intravenous Magnesium Efficacy in Stroke (trial); ISIS-4, fourth international study of infarct survival; MRI, magnetic resonance imaging; NMDA, N-methyl D-aspartate; rtPA, recombinant tissue plasminogen activator 
Table 1 Animal models of focal cerebral ischaemia and magnesium treatment

\begin{tabular}{|c|c|c|c|c|}
\hline Study & Year & Model & Magnesium regimen & Infarct volume \\
\hline Izumi et $a^{56}$ & 1991 & $\begin{array}{l}\text { Permanent MCAO in Fischer-344 } \\
\text { rats }\end{array}$ & $\begin{array}{l}1 \mathrm{mmol} / \mathrm{kg} \text { before and } 1 \text { hour after } \\
\text { ischaemia intraperitoneal } \mathrm{MgCl}_{2}\end{array}$ & $\begin{array}{l}-26 \% \text { (-44\% if euglycaemia } \\
\text { maintained with insulin) }\end{array}$ \\
\hline Sjostrom and Wester ${ }^{9}$ & 1995 & Wistar rats & $2 \mathrm{mmol} / \mathrm{kg} \mathrm{IV} \mathrm{MgCl}_{2}$ & Not reported \\
\hline Marinov et a ${ }^{54}$ & 1996 & $\begin{array}{l}\text { Reversible MCAO for } 1.5 \text { or } 2 \text { hours } \\
\text { in Sprague-Dawley rats }\end{array}$ & $\begin{array}{l}30 \text { or } 90 \mathrm{mg} / \mathrm{kg} \text { intra-arterial } \\
\mathrm{MgSO}_{4}\end{array}$ & $-60 \%$ \\
\hline Schmid-Elsaesser et $a^{57}$ & 1999 & $\begin{array}{l}\text { Transient MCAO for } 1.5 \text { hours in } \\
\text { Sprague-Dawley rats }\end{array}$ & $\begin{array}{l}1 \mathrm{mmol} / \mathrm{kg} \mathrm{MgCl} \\
\text { at reperfusion }\end{array}$ & $\begin{array}{l}-25 \% \text { (significant cortical infarct } \\
\text { volume reduction but non-significant } \\
\text { total infarct volume reduction) }\end{array}$ \\
\hline Yang et $a^{55}$ & 2000 & Thromboembolic MCAO in rats & $\begin{array}{l}90 \mathrm{mg} / \mathrm{kg} \mathrm{IV} \mathrm{MgSO}_{4} 2,6 \text {, or } 8 \\
\text { hours after onset of ischaemia }\end{array}$ & $-61 \%$ \\
\hline
\end{tabular}

major central nervous system side effects including psychotomimetic potential, sedation and hallucinations, as well as dose limiting cardiovascular effects. ${ }^{2122}$ However, since magnesium is, in practice, likely to be prepared by local pharmacies, care must be taken over the chemistry. Confusion has arisen from magnesium dosing by weight rather than using SI units, since magnesium sulphate exists either as a heptahydrated or anhydrous salt, with molecular weights of 246 and 120 respectively, and there is therefore a risk that double or half of the intended dose may be prepared. ${ }^{23}$

\section{POTENTIAL MECHANISMS OF ACTION}

There are numerous possible modes of action for magnesium in protecting neurones and glia from ischaemic damage. Reduction of cerebral infarct volume by magnesium may be consequent to effects on cerebral blood flow, or primarily neuronal actions, or more probably through a combination of these effects.

After middle cerebral artery occlusion, a core region where blood flow falls below around $10 \mathrm{ml} / 100 \mathrm{~g} / \mathrm{min}$ (corresponding to the end arterial middle cerebral artery supply) rapidly necroses. The surrounding region of ischaemia, where collateral flow supports blood flows of $10-20 \mathrm{ml} / 100 \mathrm{~g} / \mathrm{min}$ is known as the ischaemic penumbra. ${ }^{24}{ }^{25}$ The metabolic and neurochemical consequences of ischaemia set in chain a complex range of processes that, unless interrupted by reperfusion or (at least experimentally) by neuroprotective drugs, will result in the death of the penumbra. These processes include excessive release of neurotransmitters, particularly glutamate, excessive activation of post-synaptic glutamate receptors (including the $N$-methyl D-aspartate (NMDA) receptor), excessive sodium and calcium ion entry to cells via ligand and voltage gated channels, and activation of calcium dependent intracellular enzyme systems, that lead to free radical production, membrane lipid breakdown, proteolysis, upregulation of specific genes, and the initiation of both apoptosis and an inflammatory response.

In experimental systems, magnesium antagonises many of these processes. Magnesium ions are antiexcitotoxic through inhibition of ischaemia-induced glutamate release, ${ }^{26}$ and through antagonist properties at the NMDA receptor ion channel, ${ }^{27-29}$ where magnesium ions provide a physiological voltage dependent block. ${ }^{30}$ Magnesium antagonises calcium entry via voltage gated channels of all types, enhances mitochondrial buffering of excessive calcium, ${ }^{31}$ and may prevent depletion of ATP. ${ }^{32}$ Intracellular magnesium concentrations in experimental systems are sufficiently high to antagonise a number of voltage gated ion channels including calcium, sodium and potassium, ${ }^{29}$ all implicated in cerebral ischaemia. Despite doubts about brain penetrance by systemically administered magnesium based on its pharmacokinetics, animal evidence that intravenous, intramuscular, oral, or intraperitoneal magnesium ameliorates direct excitotoxic brain injury induced by injection of NMDA, ${ }^{33}$ prevents NMDA induced seizures, ${ }^{34}{ }^{35}$ increases free brain magnesium after head trauma, ${ }^{36}$ modifies NMDA receptor binding characteristics, ${ }^{37}$ and supports a potential neuronal mechanism of action in ischaemia.

In addition to the neuronal effects, magnesium also has a number of vascular effects that may be pertinent, particularly antagonism of vasoconstrictive mediators (for example endothelin-1), ${ }^{38-40}$ enhanced cerebral blood flow ${ }^{41}$ presumably consequent to vasodilatation of cerebral blood vessels ${ }^{42}$ - and increased cardiac output. ${ }^{43}{ }^{44}$ Magnesium concentrations within the usual "therapeutic range" prolong bleeding time, ${ }^{45}$ but no clinical consequences of this have been noted, even in ISIS-4 where concomitant thrombolysis and aspirin were frequently used.

\section{ANIMAL MODELS}

In vivo, magnesium ameliorates histological damage in models of global forebrain ischaemia, focal head injury, subarachnoid haemorrhage, and spinal cord ischaemia. ${ }^{46-50}$ It improves behavioural or functional outcomes after head injury or spinal cord ischaemia, ${ }^{3648}$ prevents seizures provoked by various chemical or electrical stimuli, ${ }^{745152}$ and antagonises a range of vasoconstrictive mediators that may be relevant to focal brain ischaemia. ${ }^{38-40}$ In vitro, magnesium prevents anoxic axonal injury. ${ }^{53}$

The most relevant model for human stroke is temporary or permanent middle cerebral artery occlusion, usually in rats. Magnesium has been tested in different models, by different investigators, and in different laboratories. This diversity of models and laboratories was a key recommendation in attempts to improve neuroprotective drug development. ${ }^{2}$

Results are summarised in table 1. Magnesium sulphate consistently reduces cerebral infarct volume after middle cerebral artery occlusion, with evidence of a dose response effect $^{54}$ within readily achieved serum levels, and a prolonged time window of up to six hours after onset of ischaemia, ${ }^{55}$ which is highly favourable for a neuroprotective drug. Rat serum levels of $1.49 \mathrm{mmol} / \mathrm{l}$ after a $90 \mathrm{mg} / \mathrm{kg}$ intra-arterial dose are associated with up to $60 \%$ infarct volume reduction, and retain efficacy when administration is delayed for six hours after onset of ischaemia. ${ }^{545}$ The same dose has antiexcitotoxic activity in a rat seizure model. Average infarct volume reductions in rats range from $25 \%$ to $61 \%$. Hyperglycaemia in rodents given magnesium chloride attenuates neuroprotection, ${ }^{56}$ but this has not been reported in humans and has not been seen in animals given magnesium sulphate. There is evidence of improved functional outcome and reduced mortality ${ }^{54}$ in magnesium treated animals.

\section{HUMAN TRIALS}

A systematic review of neuroprotective agents modulating glutamate action disclosed six randomised, controlled trials of magnesium in stroke, including 716 participants. Unfortunately, data are available for five trials of only 206 patients, ${ }^{58-62}$ 


\section{Box 1: Key features of the IMAGES trial}

- Time window <12 hours after stroke onset.

- Inclusions: stroke with limb weakness.

- Exclusions: coma, renal impairment, pregnancy.

- Placebo or intravenous magnesium sulphate: $16 \mathrm{mmol}$ loading infusion, then $65 \mathrm{mmol}$ over 24 hours.

- Central randomisation via minimisation algorithm to ensure balance of prognostic factors.

- Outcome data (Barthel index and modified Rankin scale) at 30 and 90 days

- Primary outcome: proportion of patients dead or dependent at 90 days.

- $80 \%$ power to detect $5.5 \%$ absolute difference in death or dependence; also has $80 \%$ power to detect a $7 \%$ absolute difference in outcome for patients treated within six hours of stroke.

- Magnetic resonance imaging (MRI) substudy to detect $25 \%$ difference in proportion of patients with infarct expansion between pretreatment diffusion weighted MRI and 90 day T2 weighted MRI.

and only four report data suitable for formal meta-analysis. ${ }^{63}$ All trials have reported reduction in the end point of death or dependence, but small numbers mean that this finding lacks statistical significance, and results must be interpreted with caution: stroke is highly heterogeneous and minor baseline differences in characteristics may explain the apparent outcome effect. Systematic review of four trials yields an odds ratio for poor outcome (death or dependence at 3-6 month follow up) of 0.67 (95\% confidence interval 0.35 to 1.26 ), with an absolute reduction of $8 \%$ (95\% confidence interval $24 \%$ decrease to $7 \%$ increase). ${ }^{58-61}{ }^{64}$ Greater neurological improvement over 30 days after stroke in the magnesium group was reported in the trial of Lampl and colleagues, ${ }^{62}$ but outcomes are not presented in a manner amenable to inclusion in metaanalysis. There are uncertainties about the randomisation, control and blinding procedures in the largest trial, which has reported only unconventional outcome measures of uncertain relevance to stroke (mini-mental state examination and limb power on the Medical Research Council scale). ${ }^{65}$ A small open trial (Field Administration of Stroke Treatment-Magnesium, FAST-MAG) confirms the feasibility of pre-hospital magnesium administration by paramedics with appropriate training in diagnosis of acute stroke, and a full scale trial of treatment initiated within two hours of stroke onset is planned. ${ }^{66}$

Most clinical trials have administered magnesium as an intravenous loading infusion, usually over 15 minutes, followed by a maintenance infusion over 24 hours or longer. Serum levels, where reported, have been predominantly within the therapeutic range suggested by animal models (mean serum concentration $1.55 \mathrm{mmol} / \mathrm{l}$ in two trials). Higher loading doses ensure that the majority of patients achieve presumed therapeutic levels rapidly. ${ }^{60} \mathrm{~A}$ minor reduction in diastolic blood pressure at 24 hours has been reported, but no significant haemodynamic sequelae have been described.

The results of these small trials are encouraging, and have informed the sample size calculations for a large ongoing trial, the Intravenous Magnesium Efficacy in Stroke (IMAGES) trial. ${ }^{67}$ IMAGES is a multicentre study involving over 130 centres worldwide, and has now recruited over 2200 participants within 12 hours of stroke onset. Results are expected in 2003. Key features of the IMAGES trial design are described in box 1 .

Viewed from the perspective gained from a decade of failed neuroprotective studies in stroke, the design of IMAGES may be criticised. In particular, the time window of 12 hours after stroke onset must now be regarded as optimistic, despite both favourable animal data for magnesium compared with many other drugs, and trends toward benefit for another neuroprotective drug with extended time window, citicoline ${ }^{68}$ However, the sample size planned for IMAGES is larger than for any other individual neuroprotective trial to date, and the a priori assumption of around one third of patients being treated within the first six hours has been exceeded. Academic levels of funding-investigators receive about $1 \%-2 \%$ of the amount provided by commercially sponsored acute stroke trials per patient entered in IMAGES-have necessitated the participation of many small stroke centres, and many countries not usually involved in acute stroke trials, with potentially greater generalisability of results. Coadministration of recombinant tissue plasminogen activator (rtPA) is allowed, and IMAGES may therefore provide useful data in an area hitherto not extensively studied. There are clear theoretical advantages in combination therapy, with the possibilities that neuroprotective drugs may extend tissue viability and enhance the benefit or extend the time window for thrombolysis, and conversely, that reperfusion may enhance drug delivery and benefit from neuroprotection. Animal data support this view. ${ }^{69} 70$ A substudy using magnetic resonance imaging (MRI) parameters to assess treatment effect (MR-IMAGES) aims to recruit 150 patients and again may provide further insight. MRI studies with other neuroprotective agents reinforce the belief that MRI lesion volume provides a viable biomarker for activity ${ }^{68}$ Finally, the FAST-MAG trial should provide the most rigorous test of neuroprotection ever undertaken with its protocol for pre-hospital treatment.

\section{CONCLUSIONS}

Magnesium is a promising neuroprotective agent. The preclinical profile is superior to many previously investigated compounds, and is robust in the hands of different investigators. Clinical experience is extensive in other therapeutic areas and the pharmacokinetics and safety profile of magnesium are already widely known. Large academically funded clinical trials in acute ischaemic stroke are ongoing after favourable trends in small trials. The IMAGES trial and its MRI substudy are expected to report in 2003, and the FAST-MAG programme thereafter may provide the most rigorous test of any neuroprotective agent yet undertaken.

\section{QUESTIONS (TRUE (T)/FALSE (F); ANSWERS AT END OF REFERENCES)}

\section{Q1. Concerning magnesium physiology:}

(A) Cerebrospinal fluid magnesium concentration is in equilibrium with that in serum

(B) Brain magnesium is predominantly in the free, ionised form

(C) Magnesium is excreted renally

(D) Hypermagnesaemia is associated with slowed cardiac conduction

(E) Depression of deep tendon reflexes occurs with hypermagnesaemia

\section{Q2. Neuroprotective agents for stroke treatment:}

(A) Have a well established role

(B) Are contraindicated in patients given rtPA

(C) Are thought to prevent cell death in the infarct core

(D) May limit expansion of lesions on MRI

(E) Share a common mechanism of action

Q3. Possible neuroprotective actions of magnesium include:

(A) Inhibition of glutamate release

(B) L-type calcium channel block

(C) NMDA receptor activation

(D) Antiaggregatory effects on platelets 
(E) AMPA receptor antagonism

\section{Q4. Concerning magnesium in animal models of stroke:}

(A) Infarct volume is reduced if treatment is delayed by up to six hours

(B) The chloride salt is less effective than the sulphate

(C) Hyperglycaemia may be induced

(D) Neuroprotection is evident only at doses that cause neuromuscular blockade

(E) Is only effective if the blood-brain barrier has broken down

\section{Q5. Clinical trials of magnesium have demonstrated:}

(A) Unequivocal benefit in acute myocardial infarction

(B) Superiority to other agents in prevention of eclamptic seizures

(C) Reduced risk of death or dependence after stroke

(D) Increased risk of bleeding

(E) Benefit in subarachnoid haemorrhage and head injury

\section{REFERENCES}

1 Gorelick PB. Neuroprotection in acute ischaemic stroke: a tale of for whom the bell tolls? Lancet 2000;355:1925-6.

2 Stroke Therapy Academic Industry Roundtable (STAIR) Recommendations for standards regarding preclinical neuroprotective and restorative drug development. Stroke 1999;30:2752-8.

3 Muir KW, Grosset DG. Neuroprotection for acute stroke: making clinical trials work. Stroke 1999:30:180-2.

4 Samsa GP, Matchar DB. Have randomized controlled trials of neuroprotective drugs been underpowered? An illustration of three statistical principles. Stroke 2001;32:669-74

5 Ebel H, Gunther T. Magnesium metabolism: a review. J Clin Chem Clin Biochem 1980;18:257-70.

6 Oppelt WW, Maclntyre I, Rall DP. Magnesium exchange between blood and cerebrospinal fluid. Am J Physiol 1963;205:959-62.

7 Hallak M, Berman RF, Irtenkauf SM, et al. Peripheral magnesium sulfate enters the brain and increases the threshold for hippocampal seizures in rats. Am J Obstet Gynecol 1992;167:1605-10.

8 Fuchs-Buder T, Tramer MR, Tassonyi E. Cerebrospinal fluid passage of intravenous magnesium sulfate in neurosurgical patients. J Neurosurg Anesthesiol 1997;9:324-8

9 Sjostrom LG, Wester P. Accumulation of magnesium in rat brain after intravenously induced hypermagnesemia. Cerebrovasc Dis 1995;5:241.

10 Helpern JA, Vande Linde AM, Welch KM, et al. Acute elevation and recovery of intracellular $[\mathrm{Mg} 2+]$ following human focal cerebral ischemia. Neurology 1993;43:1577-81.

11 Iseri LT, French JH. Magnesium: nature's physiologic calcium blocker. Am Heart J 1984; 108: 188-93.

12 Chien PF, Khan KS, Arnott N. Magnesium sulphate in the treatment of eclampsia and pre- eclampsia: an overview of the evidence from randomised trials. Br J Obstet Gynaecol 1996;103:1085-91.

13 Di Napoli M, Papa F. Inflammation, hemostatic markers, and antithrombotic agents in relation to long-term risk of new cardiovascular events in first-ever ischemic stroke patients. Stroke 2002;33:1763-71.

14 Teo KK, Yusuf S, Collins R, et al. Effects of intravenous magnesium in suspected acute myocardial infarction: an overview of the randomised trials. BM 1991;303:1499-503.

15 Woods KL, Fletcher S, Roffe C, et al. Intravenous magnesium sulphate in suspected acute myocardial infarction: results of the second Leicester Intravenous Magnesium Intervention Trial (LIMIT-2). Lancet 1992;339: 1553-8

16 ISIS-4 Collaborative Group. ISIS-4: a randomised factorial trial assessing early oral captopril, oral mononitrate, and intravenous magnesium sulphate in 58050 patients with suspected acute myocardial infarction. Lancet 1995;345:669-85

17 Shechter $M$, Hod H, Chouraqui $\mathrm{P}$, et al. Magnesium therapy in acute myocardial infarction when patients are not candidates for thrombolytic therapy. Am J Cardiol 1995;75:321-3.

18 Rationale and design of the magnesium in coronaries (MAGIC) study. A clinical trial to reevaluate the efficacy of early administration of magnesium in acute myocardial infarction. The MAGIC Steering Committee. Am Heart J 2000;139(1 pt 1):10-14.

19 Sibai BM, Graham JM, McCubbin JH. A comparison of intravenous and intramuscular magnesium sulfate regimens in preeclampsia. Am J Obstet Gynecol 1984;150:728-33.

20 Somjen G, Hilmy M, Stephen CR. Failure to anesthetize human subjects by intravenous administration of magnesium sulfate. J Pharmacol Exp Ther 1966;154:652-9.
21 Davis SM, Lees KR, Albers GW, et al. Selfotel in acute ischemic stroke: possible neurotoxic effects of an NMDA antagonist. Stroke 2000;31:347-54.

22 Lees KR. Cerestat and other NMDA antagonists in ischemic stroke. Neurology 1997:49(5 suppl 4):S66-9.

23 Ramsay S. Getting the chemistry right in trials. Lancet 1998;351:1528.

24 Astrup J, Siesjo BK, Symon L. Thresholds in cerebral ischemia-the ischemic penumbra. Stroke 1981;12:723-5.

25 Baron JC. Perfusion thresholds in human cerebral ischemia: historical perspective and therapeutic implications. Cerebrovasc Dis 2001;11(suppl 1):2-8

26 Smith DAS, Connick JH, Stone TW. Effect of changing extracellular levels of magnesium on spontaneous activity and glutamate release in the mouse neocortical slice. Br J Pharmacol 1989;97:475-82.

27 Harrison NL, Simmonds MA. Quantitative studies on some antagonists of $\mathrm{N}$-methyl D-aspartate in slices of rat cerebral cortex. Br J Pharmacol 1985:84:381-91.

28 Johnson JW, Ascher P. Voltage-dependent block by intracellular Mg2+ of N-methyl-D-aspartate-activated channels. Biophys J 1990;57:108590.

29 Brocard JB, Rajdev S, Reynolds IJ. Glutamate-induced increases in intracellular free $\mathrm{Mg} 2+$ in cultured cortical neurons. Neuron 1993;11:751-7.

30 Nowak L, Bregestovski $P$, Ascher $P$, et al. Magnesium gates glutamate-activated channels in mouse central neurones. Nature 1984;307:462-5

31 Favaron $M$, Bernardi $P$. Tissue-specific modulation of the mitochondrial calcium uniporter by magnesium ions. FEBS Lett 1985;183:260-4.

32 McIntosh TK, Faden Al, Yamakami I, et al. Magnesium deficiency exacerbates and pretreatment improves outcome following traumatic brain injury in rats: $31 \mathrm{P}$ magnetic resonance spectroscopy and behavioral studies. J Neurotrauma 1988;5:17-31

33 McDonald JW, Silverstein FS, Johnston MV. Magnesium reduces $\mathrm{N}$-methyl-D-aspartate (NMDA)-mediated brain injury in perinatal rats Neurosci Lett 1990;109:234-8.

34 Mason BA, Standley CA, Irtenkauf SM, et al. Magnesium is more efficacious than phenytoin in reducing $\mathrm{N}$-methyl-D-aspartate seizures in rats. Am J Obstet Gynecol 1994;171:999-1002.

35 Decollogne S, Tomas A, Lecerf $C$, et al. NMDA receptor complex blockade by oral administration of magnesium: comparison with MK-801. Pharmacol Biochem Behav 1997;58:261-8.

36 Heath DL, Vink R. Magnesium sulphate improves neurologic outcome following severe closed head injury in rats. Neurosci Lett 1997;228: 175-8

37 Hallak $M$. Effect of parenteral magnesium sulfate administration on excitatory amino acid receptors in the rat brain. Magnes Res 1998;11:117-31.

38 Aisenbrey GA, Corwin E, Catanzarite V. Effect of magnesium sulfate on the vascular actions of norepinephrine and angiotensin II. Am J Perinatol 1992;9:477-80.

39 Kemp PA, Gardiner SM, Bennett T, et al. Magnesium sulphate reverses the carotid vasoconstriction caused by endothelin-l, angiotensin II and neuropeptide-Y, but not that caused by N(G)-nitro-L-arginine methyl ester in conscious rats. Clin Sci 1993;85:175-81.

40 Torregrosa G, Perales AJ, Salom JB, et al. Different effects of $\mathrm{Mg} 2+$ on endothelin-1- and 5- hydroxytryptamine-elicited responses in goat cerebrovascular bed. J Cardiovasc Pharmacol 1994;23:1004-10.

41 Chi OZ, Pollak P, Weiss HR. Effects of magnesium sulfate and nifedipine on regional cerebral blood flow during middle cerebral artery ligation in the rat. Arch Int Pharmacodyn Ther 1990;304:196-205.

42 Belfort MA, Moise KJ Jr. Effect of magnesium sulfate on maternal brain blood flow in preeclampsia: a randomized, placebo-controlled study. Am J Obstet Gynecol 1992;167:661-6.

43 Rasmussen HS, Larsen OG, Meier K, et al. Hemodynamic effects of intravenously administered magnesium on patients with ischemic heart disease. Clin Cardiol 1988;11:824-8.

44 Reinhart RA. Clinical correlates of the molecular and cellular actions of magnesium on the cardiovascular system. Am Heart J 1991;121:151321.

45 Ravn HB, Vissinger $\mathrm{H}$, Kristensen SD, et al. Magnesium inhibits platelet activity-an infusion study in healthy volunteers. Thromb Haemost 1996;75:939-44.

46 Okawa M. [Effects of magnesium sulfate on brain damage by complete global brain ischemia]. Masui-Japanese Journal of Anesthesiology 1992:41:341-55

47 Mclntosh TK, Vink R, Yamakami I, et al. Magnesium protects against neurological deficit after brain injury. Brain Res 1989;482:252-60.

48 Feldman Z, Gurevitch B, Artru AA, et al. Effect of magnesium given 1 hour after head trauma on brain edema and neurological outcome. J Neurosurg 1996;85:131-7.

49 van den Bergh W, Zuur K, Kamerling N, et al. Magnesium reduces depolarization time and lesion volume after subarachnoid hemorrhage in the rat. Cerebrovasc Dis 2001;11(suppl 4): 109

50 Follis F, Miller K, Scremin OU, et al. NMDA receptor blockade and spinal cord ischemia due to aortic crossclamping in the rat model. Can $J$ Neurol Sci 1994;21:227-32.

51 Borges LF, Gucer G. Effect of magnesium on epileptic foci. Epilepsia 1978;19:81-91.

52 Cotton DB, Hallak M, Janusz C, et al. Central anticonvulsant effects of magnesium sulfate on N-methyl-D-aspartate-induced seizures. Am J Obstet Gynecol 1993; 168(3 pt 1):974-8.

53 Stys PK, Ransom BR, Waxman SG. Effects of polyvalent cations and dihydropyridine calcium channel blockers on recovery of CNS white matter from anoxia. Neurosci Lett 1990;1 15:293-9. 
54 Marinov MB, Harbaugh KS, Hoopes PJ, et al. Neuroprotective effects of preischemia intraarterial magnesium sulfate in reversible focal cerebral ischemia. J Neurosurg 1996;85:117-24.

55 Yang Y, Li Q, Ahmad F, et al. Survival and histological evaluation of therapeutic window of post- ischemia treatment with magnesium sulfate in embolic stroke model of rat. Neurosci Lett 2000;285:1 19-22.

56 Izumi Y, Roussel S, Pinard E, et al. Reduction of infarct volume by magnesium after middle cerebral artery occlusion in rats. J Cereb Blood Flow Metab 1991;11:1025-30.

57 Schmid-Elsaesser $\mathbf{R}$, Zausinger $\mathrm{S}$, Hungerhuber $\mathrm{E}$, et al. Neuroprotective effects of combination therapy with tirilazad and magnesium in rats subjected to reversible focal cerebral ischemia. Neurosurgery 1999;44:163-71.

58 Wester PO, Asplund K, Eriksson S, et al. Infusion of magnesium in patients with acute brain infarction. Acta Neurol Scand 1984:70:143.

59 Muir KW, Lees KR. A randomised, double-blind, placebo-controlled pilot trial of intravenous magnesium sulfate in acute stroke. Stroke 1995;26: 183-8.

60 Muir KW, Lees KR. Dose optimization of intravenous magnesium sulfate after acute stroke. Stroke 1998;29:918-23.

61 IMAGES Study Group, Bradford APJ, Muir KW, Lees KR. IMAGES pilot study of intravenous magnesium in acute stroke. Cerebrovasc Dis 1998;8(suppl 4):86

62 Lampl Y, Gilad R, Geva D, et al. Intravenous administration of magnesium sulfate in acute stroke: a randomized double-blind study. Clin Neuropharmacol 2001;24:11-15.

63 Muir KW. Magnesium for neuroprotection in ischaemic stroke: rationale for use and evidence of effectiveness. CNS Drugs 2001;15:921-30.
64 Muir KW, Lees KP. Systematic review of glutamate antagonists in acute stroke. Stroke 2002;33:386

65 Galeas T, Contos T, Exarhos $\mathrm{P}$, et al. The role of magnesium $(\mathrm{Mg})$ a natural calcium (Ca) antagonist in the treatment of acute ischaemic stroke (clinical study). Cerebrovasc Dis 1999;9(suppl):102.

66 Saver JL, Kidwell CS, Leary MC, et al. Results of the Field Administration of Stroke Treatment-Magnesium (FAST-MAG) pilot trial: a study of prehospital neuroprotective therapy. Stroke 2002;33:353.

67 Bradford APJ, Lees KR. Design of the Intravenous Magnesium Efficacy in Acute Stroke (IMAGES) trial. Current Controlled Trials in Cardiovascular Medicine 2000;1:184-90.

68 Warach S, Pettigrew LC, Dashe JF, et al. Effect of citicoline on ischemic lesions as measured by diffusion- weighted magnetic resonance imaging Citicoline 010 Investigators. Ann Neurol 2000;48:713-22.

69 Sereghy T, Overgaard K, Boysen G. Neuroprotection by excitatory amino acid antagonist augments the benefit of thrombolysis in embolic stroke in rats. Stroke 1993;24:1702-8.

70 Andersen M, Overgaard K, Meden P, et al. Effects of citicoline combined with thrombolytic therapy in a rat embolic stroke model. Stroke 1999;30:1464-71.

\section{ANSWERS}

Q1. (A) F, (B) F, (C) T, (D) T, (E) T; Q2. (A) F, (B) F, (C) F, (D)

T, (E) F; Q3. (A) T, (B) T, (C) F, (D) F, (E) F; Q4. (A) T, (B) T, (C)

$\mathrm{T}$, (D) F, (E) F; Q5. (A) F, (B) T, (C) T (but not quite significant!), (D) F, (E) F.

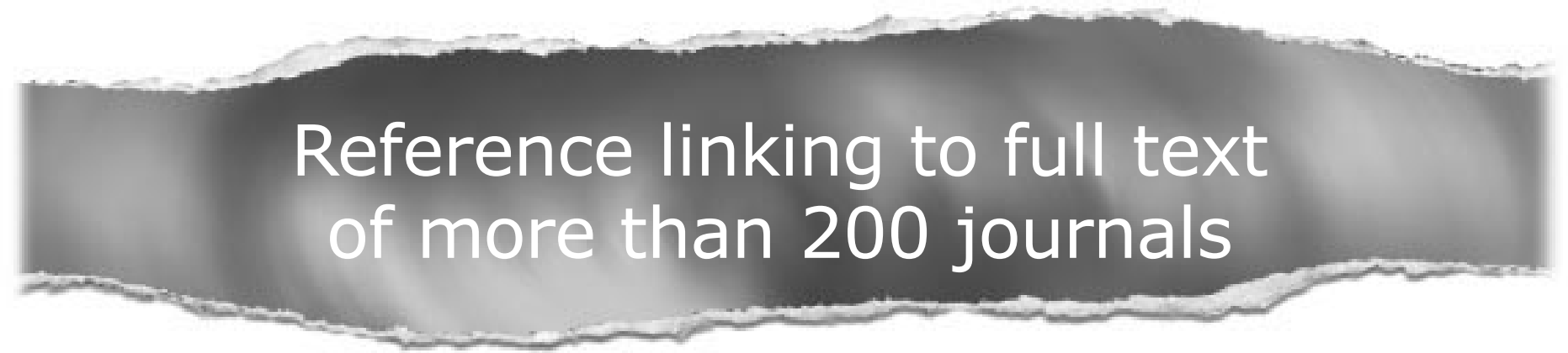

Toll free links

You can access the FULL TEXT of articles cited in Postgraduate Medical Journal online if the citation is to one of the more than 200 journals hosted by HighWire (http://highwire.stanford.edu) without a subscription to that journal. There are also direct links from references to the Medline abstract for other titles.

www.postgradmedj.com 